\title{
Bridges and barriers: globalisation and the mobility of work and workers
}

\author{
Ursula Huws
}

Ursula Huws is Professor of Labour and Globalisation in the Business School at the University of Hertfordshire and Director of Analytica Social and Economic Research, UK.

\begin{abstract}
This article starts by discussing the global division of labour. To what extent can its spatial patterns be explained by simple economic logic and to what extent is it shaped by specific features of national and local environments and corporate strategies? What factors enable restructuring, and what are the barriers to the mobility both of capital and of labour? It then introduces the articles in this issue, which display the complexity of global value chain restructuring and the ways in which it differs from popular stereotypes, as well as the common patterns that emerge. They show that restructuring is generally an incremental process, rather than a one-off change, involving mutual adaptation and accommodation to local institutional and labour market contexts. These articles do not just explore the degree to which workers consent, or resist, these changes but also look at the impacts of these decisions on the subsequent careers of those who are drawn into new positions in the global division of labour and those who are left behind.
\end{abstract}

\section{Introduction}

The development of a global division of labour has two quite distinct, though interconnected aspects: the movement of jobs to people and the movement of people to jobs. The first of these involves relocating manufacturing or back-office service activities to other regions, countries or continents, either to sites owned by the parent organisation or outsourced to another company ('offshore outsourcing'). The second involves recruiting migrant workers to do work in the original locations. In either case, employers are resorting to the same underlying strategy: tapping into a global reserve army of labour to get the work carried out more cheaply, skilfully or efficiently than before (Huws, 2006).

In each case there is a similar underpinning logic: that of modularisation. In order to co-ordinate a global value chain in which interconnected tasks are carried out in different locations, or to simplify tasks so that they can be filled by casually-employed workers with no long experience, several preconditions must be in place: the tasks must be standardised and measurable; the quality standards to which they are performed must be clearly defined and transparent; the workers must be willing and able to work to these exacting standards; and the whole process must be managed as seamlessly as 
possible, preferably using a panoptical system in which workflows and logistics can be minutely tracked ${ }^{1}$.

These preconditions cannot be put in place overnight and can often only be achieved as a result of a cumulative process of trial and error, in which the reorganisation of labour processes and obtaining of workers' consent to restructuring are gained a step at a time.

The logic of modularisation seems to lead inexorably in the direction of progressive standardisation and deskilling in which individual tasks become more and more like Lego bricks, standard components that can be reconfigured in a growing array of permutations and combinations to fit the needs of particular products, processes or customer requirements. But there are also strong counter-tendencies, engendered by the need for constant innovation and the increasingly unstable and fast-changing nature of global markets. Nevertheless, it is undoubtedly the case that, both in their own perceptions and in reality, workers across a wide range of different occupations are becoming increasingly interchangeable.

However it is one thing to perceive this economic logic in the abstract and quite another to understand how it translates into reality across actual geographical space. In any given territory, with its own unique patterns of social relations, political history, experience of colonialism, economic structure and culture, these economic forces will be welcomed, or resisted, differently. Although they are by no means symmetrical, there are both barriers to and bridges for the free flows of capital investment, goods and services across borders just as there are barriers to and bridges for the free movements of labour. And the concept of mobility does not just apply to travel across borders but must also be applied to the increasing requirements for workers to move from job to job and occupation to occupation along an increasingly unstable life-course. In other words, mobility has to be viewed in both spatial and temporal dimensions.

This issue of Work Organisation, Labour and Globalisation takes the bridges and barriers to these forms of mobility as starting points for an analysis of the new global division of labour and its impacts on workers' working conditions, livelihoods and careers. The picture that emerges is a complex one. It is clear from the ten articles that follow that patterns of international restructuring and mobility are embedded in particular national and regional contexts and shaped in multiple ways by specific locally-rooted patterns: of industrial relations, labour market characteristics, gender relations and co-operation between international companies and local institutions, including training providers. National differences must also, of course, be viewed in the larger context of US-dominated geo-political economic governance (Panitch \& Gindin, 2012). Despite these local variations, some striking common patterns also emerge.

In the first article, Pamela Meil looks at the impacts of value chain restructuring on the content of work and on conflict in highly-skilled workforces, drawing on a large body of European case studies. In doing so she exposes a number of popular myths. First, she demonstrates that offshore outsourcing is not necessarily the outcome of

$1 \quad$ Using an analysis that draws on the work of Braverman (1974) as well as the classic theories in the political economy of Smith (1776), Ricardo (1817) and Marx, (186-14; 1867), I have discussed these prerequisites in greater detail in a number of different contexts (see for instance Huws, 2012; 2007a; 2007b and Huws [ed], 2009). I will not repeat these arguments here. 
rational cost-benefit analysis but is often motivated by other factors, some of which may be arbitrary and ill-thought-out. Second, she shows that restructuring is typically an incremental process rather than a single one-off event. This process does not just involve a gradual transfer of skills and reorganisation of management structures but may also involve hierarchical realignments within value chains as companies manoeuvre to capture more added value and 'move up the chain'. Her main focus, however, is on how the content of work changes during these processes and how workers' consent, however reluctant, is obtained for restructuring, even when this may be clearly against their own interests, for instance when workers are obliged to train the people in other countries who will be taking over their jobs. Whilst paying attention to cases where workers have resisted restructuring, she concludes that such attempts have been modest, and that 'restructuring across the value chain still remains mainly a management prerogative'.

Nicole Mayer-Ahuja also draws on case study evidence, this time in two German software companies with operations in India, for her analysis of patterns of spatial mobility. This analysis, which included interviews with workers and management in both countries, makes it clear that such patterns are strongly shaped by the national context (including transport infrastructure, the housing market and family and household traditions), the structure of particular local labour markets and company strategies, which in turn are affected by the conditions of the particular markets within which they operate. Making a useful distinction between transnational mobility, everyday mobility and biographical mobility she shows how each of these varies according to these regionally-specific and company-specific factors and how each is also strongly gendered. She concludes that, again contrary to popular belief, the overall result of transnational production is 'not a general increase in spatial mobility but the re-articulation of difference under conditions of combined and uneven capitalist development'.

The third article in this collection, by Selma Venco, provides a snapshot of a new global value chain in the process of formation. Focussing, like Meil and MayerAhuja, on a high-skilled activity, she anatomises the development of the recentlyestablished trade in the processing of radiological images between Portugal and Brazil, a trade in which Portugal sometimes acts as an intermediary staging post between clinics in other parts of the world, such as Portuguese-speaking Africa. This analysis too shows a pattern in which a simple one-off transfer of work is not possible, with each party in the offshoring arrangement having to make adjustments to ensure smooth communication and management across the chain. Of particular interest is her examination of the impacts of this new source of work on the working conditions, occupational and local labour market positions of radiologists in Brazil. Here, it becomes clear that working in this offshore sector is associated with increased standardisation and pressure of work, a loss of status vis-a-vis other medical professions and a pronounced feminisation of radiology as a profession. The author concludes from this study of offshore outsourcing that, far from leading to a 'flattening' of the world, globalisation leads to a situation in which 'power relations between capital and labour are conserved and exacerbated. 
Like Meil and Mayer-A|huja, Graham Hollinshead and Jane Hardy also look at offshore outsourcing of software development, but in this case the location is Ukraine, a relatively 'new' destination in this sector. Their account provides further evidence of the strongly embedded nature of the spatial patterns that are emerging in the new global division of labour, with companies adopting a diverse range of strategies to access local skills whilst accommodating themselves to local conditions, conditions which include a very large informal economy and a legacy of oligarchy and corruption. In their analysis, they distinguish between 'structural', 'cognitive and cultural' and 'network' embeddedness. This analytical distinction makes it possible to see broader patterns, including a growing dichotomy (hidden behind a carefully-nurtured image of the 'knowledge worker') between the more creative 'architectural' functions in software development and routine activities. Whilst the former may be carried out in chic Western-style offices, with all the trappings of modernity, the latter are typically carried out in a highly casualised manner by home-based workers employed informally.

The next article, by Peter Pawlicki, also looks at outsourcing to destinations in Eastern Europe which are 'nearshore' at least as far as Western Europe is concerned. Here, the focus is on skilled engineering work in the semiconductor industry in the Czech Republic and Romania. And here too we find evidence both of the evolutionary nature of the global division of labour and of its embeddedness in local conditions. Pawlicki shows how, in the Czech Republic, the content of the work has over time become more skilled, developing into an important R\&D centre for the company, with a stable workforce, strong links to local universities to supply the requisite skills and a gradual replacement of ex-pat managers by local ones. In Romania, there was a more rapid upgrading of the work at the remote location, but this was driven by the existence of competitors in the local labour market and the need to offer attractive work in order to retain staff. However he also points to the fact that the spatial stickiness of these particular activities in these locations is contingent on very particular circumstances, arguing that in the future, 'the growing complexity of internationalisation, as well as the shifting hierarchies within the international division of labour, will result in intensified competition between particular R\&D locations. This can be especially important for locations that have until now been central, because their main competitive advantage, broad and extensive technical and organisational experience, is increasingly dwindling.

Eastern Europe makes another appearance as a source of a reservoir of cheap labour in the next article, by Malgorzata Maciejewska, but here the activity in question is not a high-skilled service job but a low-skilled job in manufacturing. And here, in a reversal of the expected pattern, the work is being outsourced not from Western Europe or the United States but from East Asia. Ex-pat managers form a recurring trope in these narratives, but in this case they are Chinese rather than European or American, whilst the workforce is European. The work which is studied here is taking place in an electronics assembly plant in a Special Economic Zone (SEZ) in Poland. The author, who carried out her research by participant observation, gives a vivid account of the conditions in this factory. This too is a tale of embeddedness, and of progressive changes in work, but here, unlike in Pawlicki's case studies, these changes involve not an improvement but a growing casualisation of the workforce and a 
worsening of conditions. These are the outcome in large part of the specific conditions of the local labour market in which there are few alternative local jobs, because of deindustrialisation and the impacts of the financial crisis. Maciejewska draws attention to the strong role played by gender both in shaping the context in which these deteriorating employment relations can occur and in determining their impacts, most acutely experienced as a shortage of time and general exhaustion. She concludes that in the face of the cheapening, flexibilisation and intensification of work in the plant, care and reproductive work becomes ever harder to perform and sustain'.

The next article, by Bjarke Refslund, looks at 'offshoring' from Denmark to Germany, on the face of it a relocation of work within Western Europe. However on further investigation this too involves the employment of a casualised workforce from Eastern Europe, only this time in the form of migrant workers employed in Germany. This case study, which concerns slaughterhouse workers processing pig meat, answers some of the questions asked by Pamela Meil in her earlier article about how and why workers resist restructuring (or fail to do so). Danish slaughterhouse workers have a long tradition of industrial militancy and, embedded as they are in a national industrial relations system which insists on national collective agreements, have repeatedly refused to accept wage cuts as part of a deal offered to them by their employers to keep the jobs in Denmark. As a result, they have kept their high wages but lost large numbers of jobs which have been moved, in successive waves, over the border into Germany where they have been filled by lower-paid, mainly migrant workers, contributing to the development of a new low-paid sector in a country not traditionally known for its low wages. As Refslund points out, whilst public attention to offshore outsourcing has been directed towards locations such as China, these European workers, who might also be regarded as victims of globalisation, have been largely unnoticed. He concludes that such understudied side-effects of European integration are likely to exert downward pressure on wages and conditions in other industries too, leading to strains on European welfare state models.

The undermining effects of global value chain restructuring on trade union militancy is also addressed in the next article, though here in a very different geographical and industrial context. Aaron Schnieder shows how past organisational efforts have created a strong trade union culture and created 'good jobs' at the Avondale shipyard in New Orleans, now faced with closure because of a global strategy of relocating shipbuilding from the USA to Asia. Drawing on a survey of Avondale workers he shows how this stable employment has enabled these workers to become active citizens, taking leadership roles in their communities and supporting a broader economy of local small businesses. He argues that the loss of these manufacturing jobs in a workplace that has for decades been the largest employer in the area will deprive the whole local economy of a tradition of active citizenship as well as damaging the prospects for individual workers and their families. It will, he suggests, leave the workers with no alternative but to take casual, seasonal jobs in low-paid service industries such as tourism.

The next article, by David Bailey and Alex De Ruyter, supplies strong evidence to support such a gloomy prognosis. These authors carried out a longitudinal study 
of another group of unionised manufacturing workers, laid off as a result of their employer's globalisation strategies, in this case the British auto workers who lost their jobs when the MG Rover factory in Birmingham was closed down in April, 2005. Whilst most of these workers did find other jobs, only a small minority of these were secure and lasting. Most had no choice but to take a series of temporary jobs, which they only found with difficulty, typically through personal contacts, with poorer wages and conditions than their previous employment and lacking coverage by union agreements. The authors speculate that some of these, relatively skilled workers may only have found work at all by displacing other, more vulnerable workers from the job market. They note that temporary agency work (TAW) is not, as often thought, the stepping-stone to a permanent job. Rather, agency workers are highly precarious and may be the first to be laid off in a recession. These research findigns suggest that globalisation strategies in one sector of a local economy lead to casualisation in other sectors.

The final article in this collection, by Fabienne Berton, is also based on a study of what happens to the workers left behind after a major restructuring. The people she describes were drawn from a lareg sample of workers who left their jobs (either through redundancy or by voluntary resignation) in France in 2006. This is, therefore, a study of the 'biographical mobility' referred to by Mayer-Ahuja in her earlier article in this collection. Berton divides her subjects into three groups: those who managed to survive and build careers in global organisations by adapting successfully to their new requirements; those who chose to retrain to enter new occupations which seemed to be more caring and more distant from the pressures of global competitiveness; and those who could not adapt and ended up unemployed. She looks in particular at the skills and personal resources that workers need to draw on in order to survive in a global corporate labour market. Those in the first group drew heavily on personal networks and used IT creatively to support their work. They accepted long hours and flexible working arrangements, behaved entrepreneurially, internalised the values of the companies they worked for and had no time for trade unions. Those in the second group explicitly rejected the values of companies they saw as profit-driven and in a permanent state of restructuring. They and their families had made sacrifices for them to retrain for jobs which, while less well paid, they saw as more personally rewarding. The third group, although they had strong technical skills, lacked the social networks and personal resources to carve out opportunities for themselves in a competitive labour market. Berton's implication is that in an era of globalisation, there will be many more like them.

What conclusions can we draw from these ten accounts of global employment restructuring? The first is that it is much easier for capital to migrate across borders than it is for labour. However capital's mobility is not effortless or cost-free. In order to establish an effective presence in a new location it has to accommodate itself to local institutions and engage with local actors, whether these are government bodies, local companies or employment or training agencies. For workers with specific soughtafter skills, there may be situations where local conditions make it possible to enter a global labour market on relatively favourable terms, but these are not necessarily 
permanent. Even if it is possible to achieve an improvement of wages and conditions in a buoyant local labour market, for instance for electronics engineers in Romania, or software developers in Bangalore, because of a strong competitiom, it should not be forgotten that these regions were originally opened up to global corporations because the wages there were significantly lower than, for instance, in California or West Germany. More usually, workers seem to be faced with the harsh choice between accepting wage reductions or losing jobs. And, once these jobs have been lost, they are more likely to be replaced by temporary and casual jobs than stable, unionised ones. The spatial mobility of work is thus reflected in a biographically mobility, with a loss of permanent occupational identities and coherent collective organisations. Historically-formed patterns of trade union organisation and negotiation, organised as they generally are at local level, have had limited efficacy in resisting these tendencies. Nevertheless, the very fact that the spatial impacts of restructuring are so varied and the patterns of globalisation so contingent on local acceptance suggest that there are many contradictory forces at play, not least those resulting from competition between countries and companies. If labour were to organise itself as internationally as capital, then the balance of forces might well be different.

(C) Ursula Huws, 2012

\section{REFERENCES}

Braverman H. (1974), Labor and monopoly capital: the degradation of work in the twentieth century, New York: Monthly Review Press.

Huws, U. (2012) 'Crisis as Capitalist Opportunity: new accumulation through public service commodification', Socialist Register.

Huws, U. (2006) 'Fixed, Footloose or fractured: work, identity and the spatial division of labour', Monthly Review, 57 (10), March.

Huws, U. (2007) 'Defragmenting: towards a critical understanding of the new global division of labour', Work organisation, Labour and Globalisation, 1 (2).

Huws, U. (2007) 'The emergence of EMERGENCE: the challenge of designing research on the new international division of labour', Work Organisation, Labour and Globalisation, 1 (2).

Huws, U., J. Flecker, M. Ramioul \& K, Guerts (2009) Value chain restructuring in Europe in a global economy, Report from the WORKS project, Leuven: Higher Institute of Labour Studies.

Marx K. (1861-64), Economic Works of Karl Marx 1861-1864, Capitalist Production as the

Production of Surplus Value. Available online at http://www.marxists.org/archive/marx/ works/1864/economic/ch02b.htm.

Marx K. (1867), Capital. Available online at: http://www.marxists.org/archive/marx/ works/1867-cl.

Panitch, L. and S. Gindin The Making of Global Capitalism: the Political Economy of American Empire, London: Verso, 2012.

Ricardo D. (1817), The principles of political economy and taxation. Available online at: http:// socserv2.socsci.mcmaster.ca/econ/ugcm/3113/ricardo/prin/index.html.

Smith A. (1776), An inquiry into the nature and causes of the wealth of nations. Available online at: http://socserv2.socsci.mcmaster.ca/econ/ugcm/3ll3/ricardo/prin/index.html. 